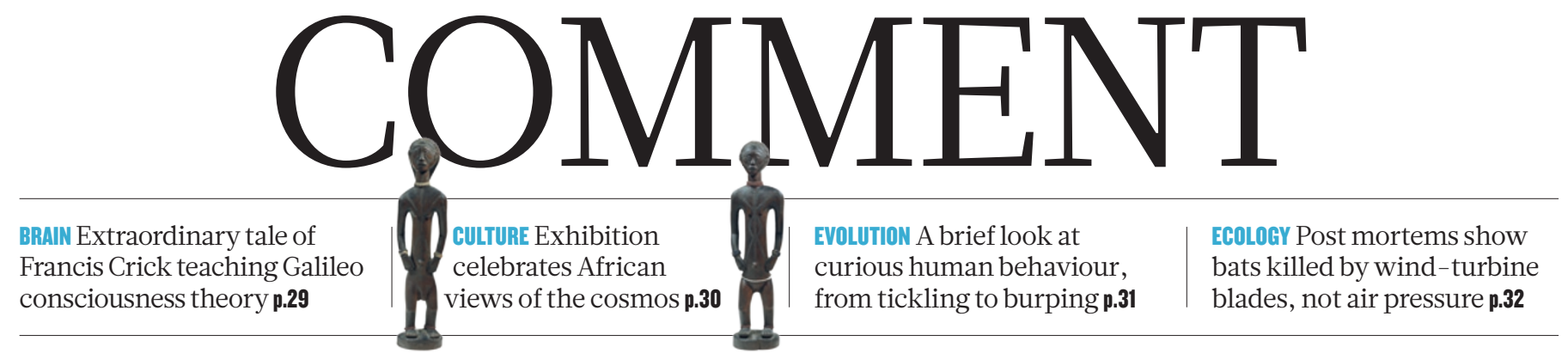

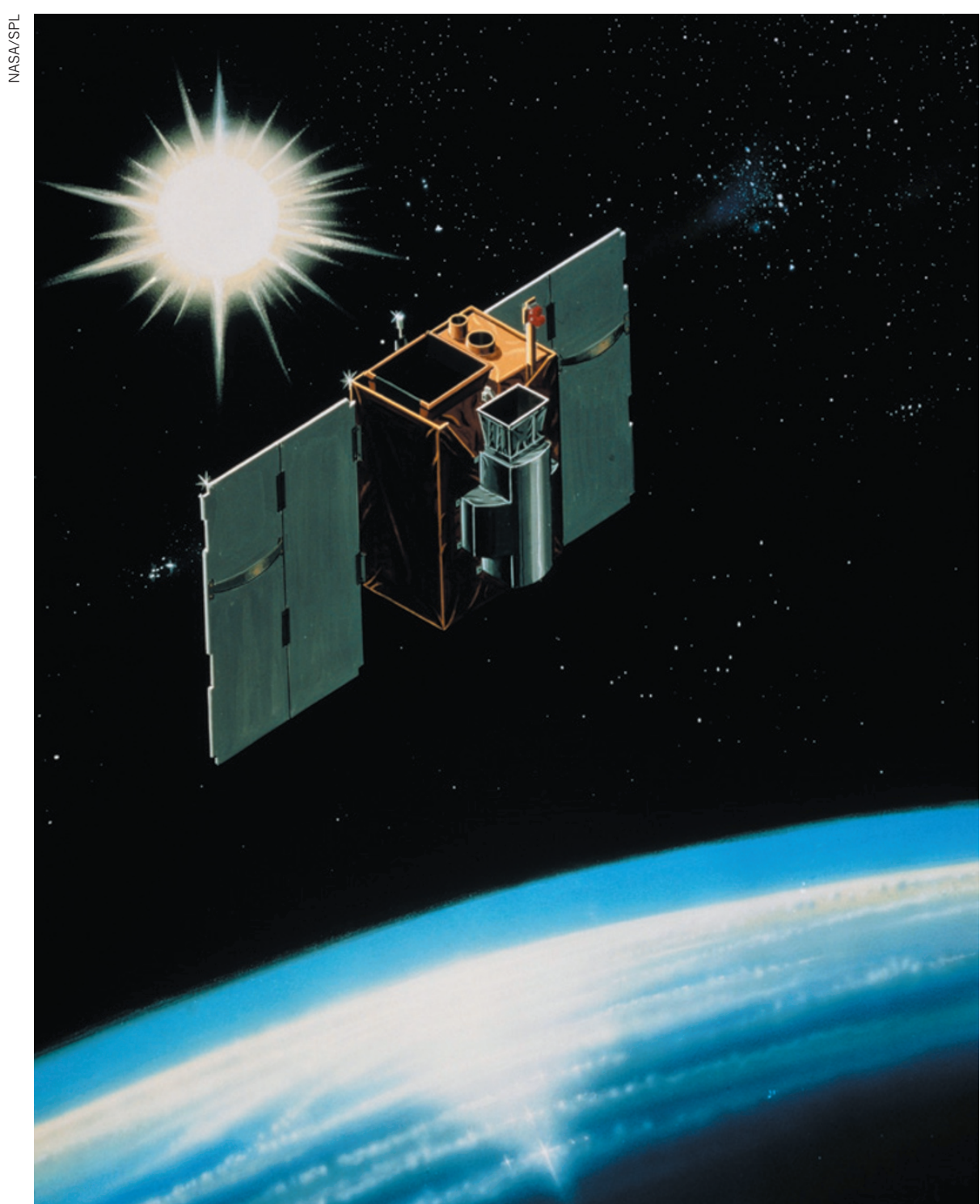

SAMPEX, the first of NASA's inexpensive Small Explorer satellites in orbit, is due back to Earth this year.

\section{Let academia lead space science}

NASA must put more of its money into thrifty missions led by principal investigators, says Daniel N. Baker.
The Mars Curiosity rover, which all space scientists fervently hope will touch down on the red planet safely this week, is a prime example of an expensive and complicated NASA mission. With a landing scheme involving 76 pyrotechnic devices firing on time and a US\$2.5-billion price tag, it is a high-risk endeavour. By contrast, the Mars Atmosphere and Volatile Evolution Mission (MAVEN) is a project being run out of our laboratory in Colorado to explore Mars's upper atmosphere and ionosphere. It is set to launch in 2013 for about $\$ 500$ million. It is on budget, on schedule and promises compelling science. Yet the Scout programme, under which such small Mars missions were funded, has recently been axed.

The planetary exploration flagship programmes and the vastly over-budget James Webb Space Telescope are symptomatic of a core problem in space research. Increasingly, NASA's focus is on big projects that promise to return tremendous science benefits. But these programmes absorb most of the available funding for space research. They shift resources away from efficient and effective principal investigators (PIs) at universities, an approach in which a single person is responsible to NASA for the success of a mission, and towards bureaucratic NASA centres. This is the wrong direction for space research, especially in a time of scarce funding.

In my opinion, we need to turn civilian space-policy thinking on its head. Missions managed by PIs should be the highest priority for NASA, not the lowest. I am not talking about the 'faster, better, cheaper' approach of the 1990s, with skeleton crews of engineers at NASA centres. I am talking about missions led by university scientists with a real passion for research. This strategy would reduce budgetary overruns, increase the frequency of launches and enhance excitement like few other things could.

\section{THREE-WAY PARTNERSHIP}

At its beginning, the US civilian space programme was crafted as a threeway partnership between government (NASA), industry and academia. From the famous 1945 report of engineer and policy adviser Vannevar Bush, Science The Endless Frontier, through to the 
unflinching commitment of NASA's second administrator, James Webb, the founding fathers of space research put universities at the centre of almost all NASA science activities.

Since then, university researchers have brought innovation and nimbleness to hardware development, have exercised tender loving care of space instruments and have provided a necessary antidote to government stagnation.

Universities have been a fertile training ground for thousands of space engineers and researchers, who have learned to be creative while sticking to budgets and schedules. This has been shown statistically in an analysis of historical data by David Bearden and his colleagues at the Aerospace Corporation in El Segundo, California, due to be published in September.

The central and indispensable role of universities in space work is now under immense stress as budgets tighten and NASA withdraws to its centres and core industry contractors. Most people who knew and understood the essential nature of the three-way space partnership are gone. Those who have replaced them in policy and leadership roles may not have realized or absorbed the lessons of the early days.

University labs are being driven out of business. In the recent 'Earth Venture' mission selection, four and a half of the five concepts selected were for missions led by NASA centres. (The half comes from a collaboration between a NASA centre and a university.) Many space hardwaredevelopment groups that were thriving as recently as five years ago are now defunct. Those that remain

\section{"University labs are being driven out of business."}

are struggling. Students are finding fewer opportunities for experimentation and are not being trained to do things cheaply in a 'hands-on' fashion. Space research has fallen into a vicious negative-feedback loop.

For example, all 15 of the high-priority missions recommended for initiation by NASA in the 2007 US National Academies' decadal survey, Earth Science and Applications from Space, are being implemented by collaborations between centres and industry. Costs for the first set of missions have ballooned by factors of two to three. According to a mid-term assessment of the survey, in-sourcing work to centres and the use of 'directed' missions rather than competitive PI-class missions were among the reasons for rising costs.

With insufficient funds, missions are being cancelled or delayed. As ageing spacecraft begin to fail, the United States is in grave danger of losing its ability to view Earth from space. Soon, it will be unable to provide decision-makers with the information they need to respond to natural hazards

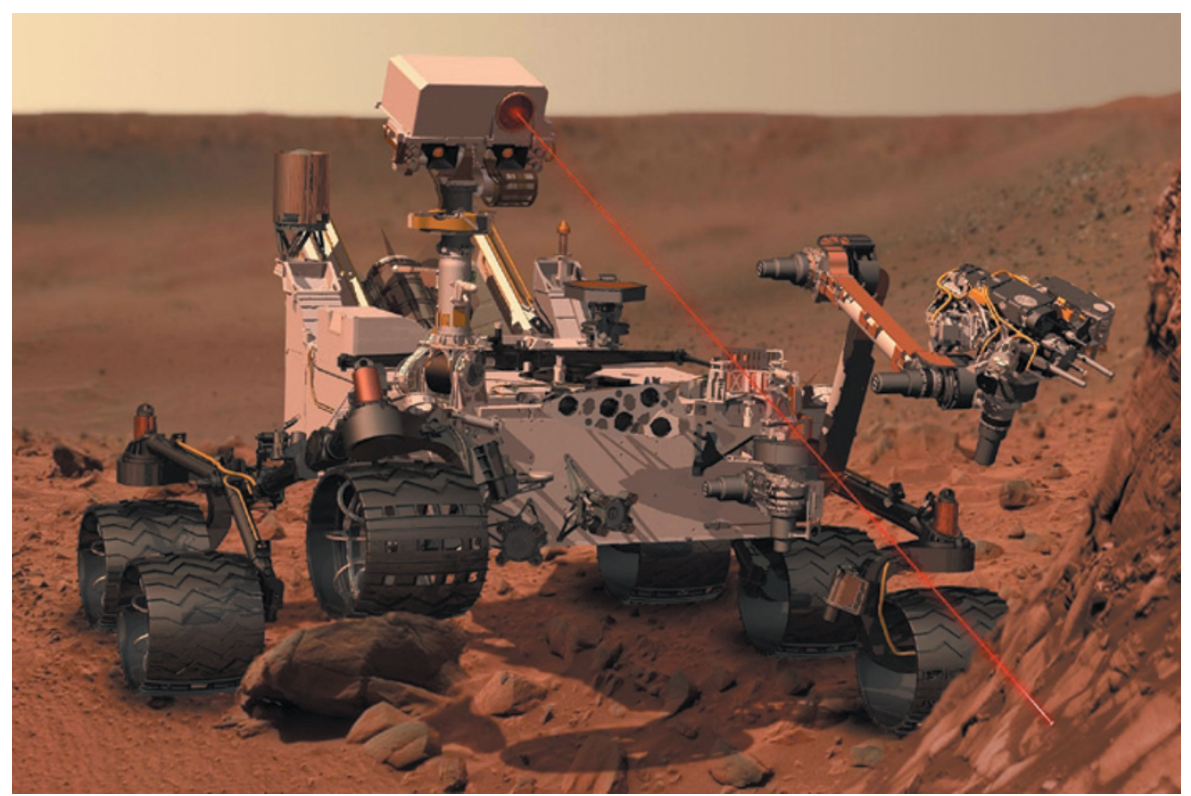

NASA's costly Curiosity rover will hopefully touch down on Mars to begin work this week.

and to the ever-increasing pace of changes that are occurring in the atmosphere, oceans, land surface, cryosphere and ecosystems.

\section{THE RIGHT BALANCE}

Some things cannot be done in modest PI mode. A dedicated flagship mission is needed to develop, for instance, the multipleinstrument spacecraft necessary for going to the challenging environments of the outer planets. The same is true for large-aperture facility-class astrophysics programmes (including the James Webb Space Telescope).

I am not arguing that NASA should gut its centres. Before my present university position, I was a laboratory director at NASA's Goddard Space Flight Center in Greenbelt, Maryland, from 1987 to 1994 . I saw firsthand what immense strengths could be mustered with a critical mass of engineering and science talent. In the current frenzy to cut federal budgets, there is a real danger of losing vital and unique capabilities at centres that have taken years to build and hone.

There have already been staff reductions, such as at the Jet Propulsion Laboratory in Pasadena, California, and the planned budget cuts mean that more losses may be in the offing. We must not allow the navigation, propulsion and communication skills that enable space to be explored to slip through our fingers. If we do, we may never again be able to traverse the rings of Saturn, nor land on an enticing asteroid - nor one day plumb the depths of Europa's oceans.

But we must not allow centres to be maintained at exorbitant staffing levels irrespective of cost. Too many institutions employ workers who are performing routine and often-unnecessary functions. I have recently seen dozens of extra managers and engineers assigned to NASA programmes just to give them accounts to charge to. Many centre-led missions are costly because they focus more on maintaining jobs than on getting the biggest scientific bang for the buck.

There is ample support in the spaceresearch community for a more balanced space programme. Many US National Research Council (NRC) reports and decadal surveys have made clear calls for more PI-led missions. And NASA's Explorer programme has used PIs to study focused space physics and astrophysics. Similarly, the Discovery and New Frontiers programmes in its Solar System exploration division are PI missions to study planetary-science issues of moderate scale. But the general trend is away from such missions.

Planning groups at NASA should work with the NRC, the other National Academies and the Office of Management and Budget to shift towards the kind of balanced programme that I advocate here. Allocating a few hundred million more dollars from NASA's \$5-billion space-research budget to the PI end of the spectrum could work wonders, in my view.

With government budgets tightening, space research should be revived in universities because they are the best places to foster innovative thinking and to get science done in an affordable way. They are also where we must train the scientists and engineers who will bring an aggressive, nimble mindset to a brighter, future NASA.

Daniel N. Baker is professor of astrophysical and planetary sciences and director of the Laboratory for Atmospheric and Space Physics at the University of Colorado, Boulder, USA. He was chief of the Laboratory for Extraterrestrial Physics at NASA's Goddard Space Flight Center from 1987 to 1994. e-mail:daniel.baker@lasp.colorado.edu 